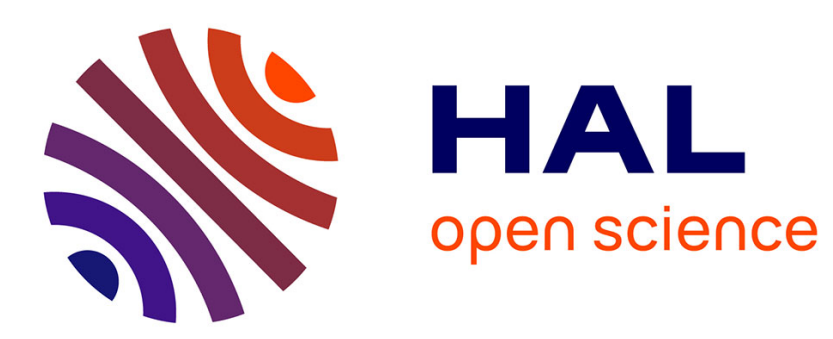

\title{
Sintering and yttrium grain boundary segregation in sub-micron grain size alumina \\ E. Sato, C. Carry
}

\section{To cite this version:}

E. Sato, C. Carry. Sintering and yttrium grain boundary segregation in sub-micron grain size alumina. Journal de Physique IV Proceedings, 1993, 03 (C7), pp.C7-1335-C7-1340. 10.1051/jp4:19937205 . jpa-00251839

\section{HAL Id: jpa-00251839 https://hal.science/jpa-00251839}

Submitted on 1 Jan 1993

HAL is a multi-disciplinary open access archive for the deposit and dissemination of scientific research documents, whether they are published or not. The documents may come from teaching and research institutions in France or abroad, or from public or private research centers.
L'archive ouverte pluridisciplinaire HAL, est destinée au dépôt et à la diffusion de documents scientifiques de niveau recherche, publiés ou non, émanant des établissements d'enseignement et de recherche français ou étrangers, des laboratoires publics ou privés. 


\title{
Sintering and yttrium grain boundary segregation in sub-micron grain size alumina
}

\author{
E. SATO and C. CARRY \\ Laboratoire de Céramique, Ecole Polytechnique Fédérale de Lausanne, MX-Ecublens, 1015 Lausanne, \\ Switzerland
}

\begin{abstract}
Sintering behavior with and without external stress was investigated using undoped and doped (1500 ppm yttria) sub-micron $\alpha$-alumina powders. The yttria doped alumina showed anomalous behavior with grain size around $0.9 \mu \mathrm{m}$, a second peak in densification rate during free sintering and a stagnation followed by a steep increase in flow stress during sinter forging. These were thought to correspond to the creep rate plateau regime and to the saturation of grain boundary with yttrium. Yttrium segregation retarded the densification during free sintering, and made the flow stress higher during sinter forging. It also lowered the grain size at which the transition occurred in the rate controlling mechanism of deformation from grain boundary diffusion to interface reaction.
\end{abstract}

\section{INTRODUCTION}

It is well known that grain boundary segregation and precipitation can strongly affect the macroscopic properties of ceramics $[1,2]$. Generally, grain boundary solute content is thermodynamically calculated from both the material solute content and an apparent free energy for segregation, without any consideration to the microstructure of the material [3]. The density of grain boundary area, however, must be considered in the case where the solubility limit in the bulk is quite small.

Recently, one of the authors proposed a simple geometrical model of segregation where all of the solute is considered to locate at grain boundaries [4]: the solute content at grain boundary is in proportion to the inverse of a grain size until it becomes over-saturated and a new phase is formed. The model was established using dense alumina ceramics doped with $500 \mathrm{ppm}$ yttria [4]. Yttrium grain boundary content varies linearly with a grain size below a given dimension, and it is independent of this above the same value, as schematically shown by the solid line of $500 \mathrm{Y}$ in Fig.1 (a). In the latter regime, inter-granular precipitation occurs. This transition strongly affects macroscopic creep behavior [5]: just below the grain-size related transition, a constant strain rate-plateau-regime is observed instead of decreasing in strain rate with increasing in grain size, as shown by the solid line of 500Y in Fig.1 (b).

The model predicts an inverse relationship between the grain size for saturation and the doping level when the solubility limit of the material is quite small. According to the relationship, it could be 
possible to obtain sub-micron or nano-grain ceramic materials [6] with a much higher doping level without grain boundary precipitation; for example, more than $1 \%$. of yttria in alumina with a grain size lower than $100 \mathrm{~nm}$ could be considered. Such highly doped ceramics with a high density of grain boundaries that exhibit solute segregation could show interesting properties at room temperature as well as at high temperature.

The purpose of this paper is to examine the effect of yttria doping into alumina with a sub-micron grain size. The expected segregation behavior of alumina doped with 1500 ppm yttria is shown as the broken line of $1500 \mathrm{Y}$ in Fig.1 (a), and a creep rate plateau regime is expected to be observed in the grain size region from 0.5 to $0.8 \mu \mathrm{m}$. The behavior of dense ceramics with such a fine microstructure has not been studied because of grain growth during hot pressing of commercial powders. Using powder compacts doped with $1500 \mathrm{ppm}$ yttria, the present authors have already observed an anomalous peak of densification rate during nonisothermal stress-free sintering at almost the same grain size with the expected transition [7]. The technique of sinter forging [8] on partly presintered specimens was adopted in this work in order to observe the mechanical behavior in sub-micron grain size range. Microstructure and flow stress evolution was analyzed to reveal the effect of yttrium grain boundary segregation on the macroscopic mechanical behavior.

\section{EXPERIMENTAL}

Commercially prepared sub-micron $\alpha$-alumina powders [Criceram, Jarrie, France] were used. The powders were doped with magnesia (500 mass ppm) and yttria $(0,500$ or 1500 mass ppm) by the supplier; they are referred as $0 Y, 500 Y$, or $1500 Y$, respectively. The main impurities are sodium, silicon and potassium, each of which is less than 50 mass ppm. Green compacts with a cylindrical shape of $15 \mathrm{~mm}$ height and $10 \mathrm{~mm}$ diameter were machined after cold-isostatic-pressing under a pressure of $250 \mathrm{MPa}$. They were all pre-sintered in a constant heating rate of $1^{\circ} \mathrm{C} / \mathrm{min}$ up to $1450^{\circ} \mathrm{C}$ to avoid rapid microstructural change at the beginning of the succeeding processes. 
The specimens were sinter forged at $1400^{\circ} \mathrm{C}$ up to several strains under air atmosphere using Instron machine; they were deformed in a constant crosshead speed condition so as to make the initial strain rate $4.5 \times 10^{-5} \mathrm{~s}^{-1}$. Some of them were sintered at $1400^{\circ} \mathrm{C}$ without external stresses in a dilatometer. After these treatments, the final density was measured, and the microstructure was observed by scanning electron microscopy on fractured surface to avoid grain growth due to thermal etching.

\section{RESULTS}

\section{Free Sintering}

Figure 2 shows the densification curves in stress-free sintering at $1400^{\circ} \mathrm{C}$. The relative density $\rho$ (upper) and its time derivative $\mathrm{d} \rho / \mathrm{d} t$ (lower) are calculated from the final density and the continuously measured shrinkage. Here, $t=0$ denotes the instant when the temperature reaches $1400^{\circ} \mathrm{C}$. The fact that yttria doping retards densification [7] is the reason why $1500 \mathrm{Y}$ has a lower initial density than $\mathrm{OY}$ after the same pre-sintering.

While the densification rate of $\mathrm{OY}$ shows a single maximum, that of $1500 \mathrm{Y}$ shows double maxima. Such double maxima are also

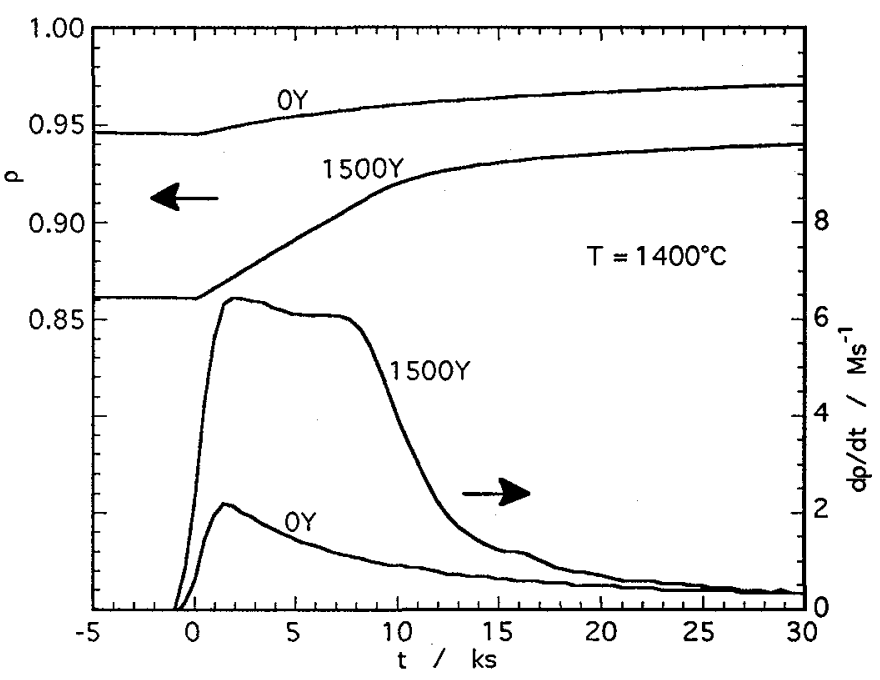

Fig.2 Isothermal densification curves in free sintering at $1400^{\circ} \mathrm{C}$. The upper and lower curves are the relative densities $\rho$, and their time derivatives $\mathrm{d} \rho / \mathrm{dt}$, respectively. observed in a constant heating rate sintering of $1500 \mathrm{Y}$ [7]. Because the pre-sintering of $1500 \mathrm{Y}$ has just stopped at the summit of the first peak in a constant heating rate sintering, the first maximum at the beginning of the subsequent isothermal sintering corresponds to the remaining tail of the first peak in the pre-sintering. The second maximum in Fig.2, therefore, corresponds to the second peak observed in constant heating rate sintering. The anomalous second peak was interpreted an effect of the transition in yttrium grain boundary state [7].

\section{Sinter Forging}

Figure 3 shows the development of the density $\rho$ (upper) and the grain size $d$ (lower) during sinter forging at $1400^{\circ} \mathrm{C}$ with an initial strain rate of $4.5 \times 10^{-5} \mathrm{~s}^{-1}$. The densities and grain sizes measured by individual specimens are shown by circles, while the solid lines show the fitted curves which will be used in further calculations. The density changes during free sintering are also shown in Fig. 3 by broken lines.

The external stress during sintering accelerates densification strongly so as to obtain almost $98 \%$ density after $6 \mathrm{ks}$ for both $0 \mathrm{Y}$ and $1500 \mathrm{Y}$. The specimens sinter forged for more than $6 \mathrm{ks}$ are, however, easy to break. This implies that many micro cracks must be introduced during the last stage of sinter forging, and that either lower strain rates or higher temperatures are needed to obtain dense ceramics.

Figure 4 shows the flow stress $\sigma$ as a function of strain $\varepsilon$ or time $t$ during sinter forging. The stress is calculated from the recorded load $P$ as follows: 


$$
\sigma=\frac{P}{S_{0}\left(1+\dot{\varepsilon}_{0} t\right)}\left(\frac{\rho}{\rho_{0}}\right)^{2 / 3},
$$

where $\dot{\varepsilon}_{0}, S_{0}, \rho_{0}$, and $\rho$ are the initial strain rate, the initial cross section, the initial density, and the density obtained from the fitted curves in Fig.3, respectively. The barreling observed in the specimens sinter forged more than $6 \mathrm{ks}$ is ignored.

Although $1500 \mathrm{Y}$ has a larger initial grain size and a lower initial density than $O Y$, it has an initial flow stress higher than $0 Y$. This implies that for the same grain size and density $0 \mathrm{Y}$ would deform more easily than $1500 Y$. The increase in stress of $1500 \mathrm{Y}$ slows down slightly at a strain of -0.17 followed by a steep increase after a strain of -0.21 : this phenomenon is highly reproducible. Such a stress evolution is not observed in $O Y$, whose stress increases constantly. The steep increase in stress of $1500 \mathrm{Y}$ starts at the grain size of $0.9 \mu \mathrm{m}$, which is close to the predicted grain size, $0.8 \mu \mathrm{m}$, where a transition in the yttrium grain boundary state could occur (see Fig.1 (a).) The stress evolution of $1500 Y$ proves the existence of a creep plateau regime in the grain size range from 0.7 to $0.9 \mu \mathrm{m}$.

\section{DISCUSSION}

In order to analyze the mechanical behavior obtained from the creep and sinter forging experiments, it is necessary to convert them into a constant strain rate condition at the same temperature. High temperature creep behavior is usually expressed by a phenomenological constitutive equation, as follows:

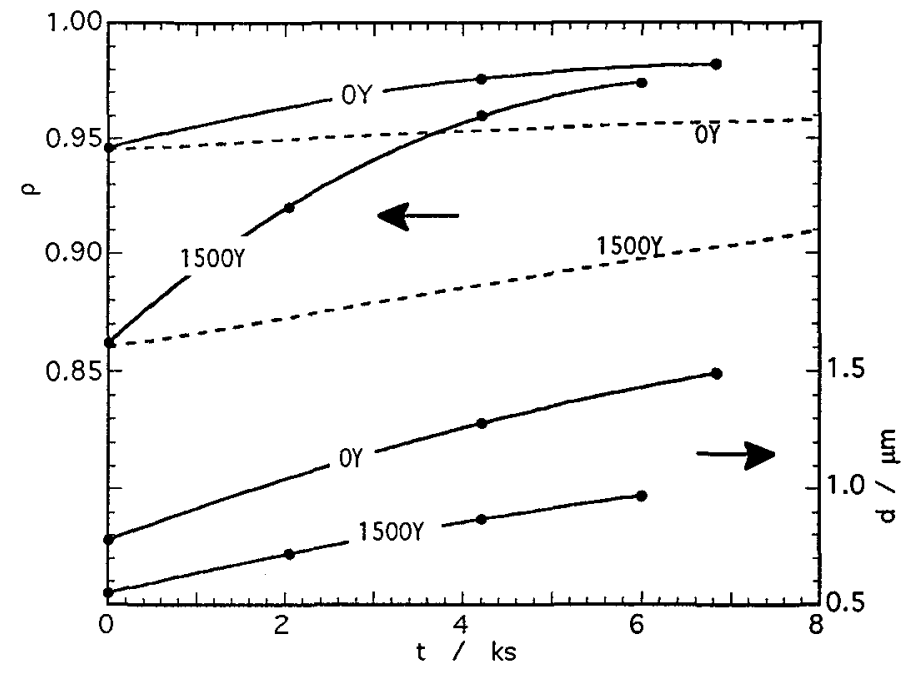

Fig.3 The densification ( $\rho$, upper part) and grain growth $(d$, lower part) behavior in sinter forging at $1400^{\circ} \mathrm{C}$ and $4.5 \times 10^{-5} \mathrm{~s}^{-1}$. The measured points are shown by circles. The densification behavior in free sintering at the same temperature is also shown by broken lines for comparison.

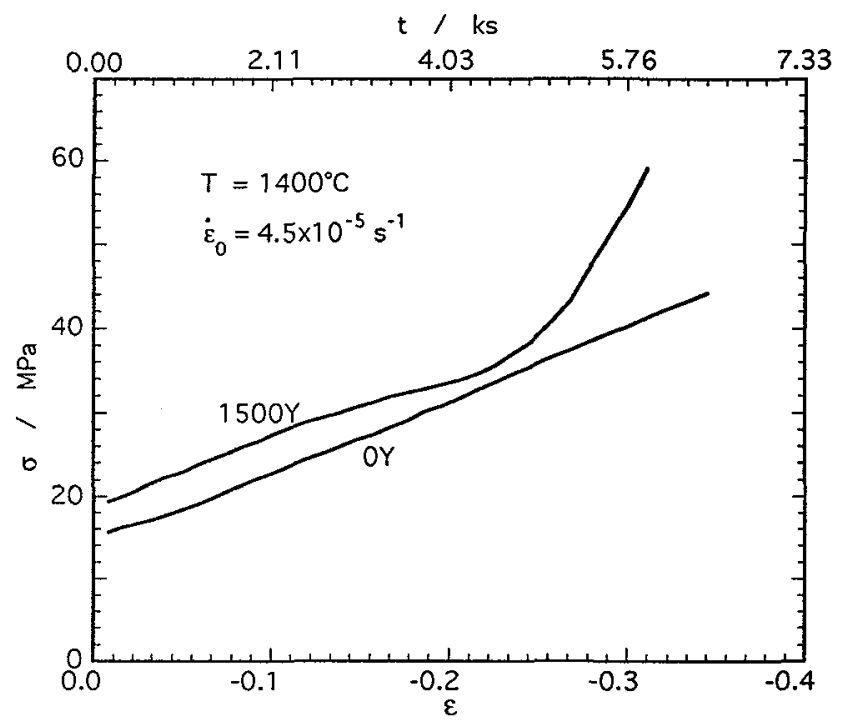

Fig.4 True stress-true strain curves in sinter forging at a temperature of $1400^{\circ} \mathrm{C}$ with an initial strain rate of $4.5 \times 10^{-5} \mathrm{~s}^{-1}$. 


$$
\dot{\varepsilon}=A \sigma^{n} d^{-p} \exp \frac{Q}{R T},
$$

where $n$ is the stress exponent, $p$ the grain size exponent, $\mathrm{Q}$ the apparent activation energy, $R$ the gas constant, and $A$ a constant. The values of $n, p$ and $Q$ were measured by Gruffel [5] and they are summarized in Table I. The creep diagram shown in Fig. 1 (b) is converted into a constant strain rate diagram at $1400^{\circ} \mathrm{C}$ and is drawn as broken lines in Fig.5. The forging data are also converted into a constant strain rate diagram using the value of $n=1.1$ and 1.6. In Fig.5, the circles correspond to the specimens whose grain sizes are measured while the solid lines connecting them are obtained from fitted lines in Fig.3.

For $0 Y$, the forging data are in fairly good agreement with the creep behavior. A slight change in slope is observed above $1 \mu \mathrm{m}$ in the forging data, which corresponds the transition from deformation controlled by interface reaction to that by grain boundary diffusion. Although the transition is drawn as a sharp change in gradient in the schematic diagrams of Figs. 1 and 5, the original creep data shows a gradual change in slope, similar to that observed in the forging data.
Table I Parameters in the constitutive equation (eq.2) obtained by Gruffel et al. [5].

\begin{tabular}{ccccc}
\hline material & grain size region & $n$ & $p$ & $Q$ \\
\hline $0 \mathrm{Y}$ & finer & 1.8 & 1.0 & $520 \mathrm{~kJ} / \mathrm{mol}$ \\
& coarser & 1.1 & 3.0 & $520 \mathrm{~kJ} / \mathrm{mol}$ \\
\hline \multirow{3}{*}{$500 \mathrm{Y}$} & finer $<1.4 \mu \mathrm{m}$ & 1.6 & 3.0 & $600 \mathrm{~kJ} / \mathrm{mol}$ \\
& plateau $1.4-2.3 \mu \mathrm{m}$ & 1.6 & 0.0 & $600 \mathrm{~kJ} / \mathrm{mol}$ \\
& coarser $>2.3 \mu \mathrm{m}$ & 1.3 & 3.0 & $800 \mathrm{~kJ} / \mathrm{mol}$ \\
\hline $1500 \mathrm{Y}$ & coarser $>0.8 \mu \mathrm{m}$ & 1.3 & 3.0 & $800 \mathrm{~kJ} / \mathrm{mol}$ \\
\hline
\end{tabular}

The forging stress of $1500 \mathrm{Y}$ shows a certain stagnation at grain sizes from 0.7 to $0.9 \mu \mathrm{m}$ and a subsequent steep increase instead of a constant increase due to grain growth. The grain size region of the stagnation is a little higher than that of the predicted plateau regime, from 0.5 to $0.8 \mu \mathrm{m}$. This discrepancy can be explained by the lower densities in the forging specimens, since yttrium segregates more strongly on remaining pore surfaces than at grain boundaries [3].

The steep increase in the forging stress of $1500 \mathrm{Y}$ is in good agreement with the steep decrease in the creep rate observed just after the plateau regime for 500Y. The deformation in 500Y is controlled by grain boundary diffusion after the plateau as well as before [5]. Since the stress observed in the finest grain size region in $1500 \mathrm{Y}$ shows much lower dependency of grain size than that for the deformation controlled by grain boundary diffusion, it can be deduced that an interface reaction controls the high 
temperature deformation of yttria doped alumina for grain sizes lower than $0.6 \mu \mathrm{m}$ as indicated by dashed-and-dotted lines in Figs. 1 and 5.

The deformation in these regions is considered to be superplastic where grain boundary sliding contributes mainly because the microstructure remains equiaxied before and after the deformation except the plateau regime [5]. The grain boundary sliding is accommodated and controlled by grain boundary diffusion except in finer grain size region where it is controlled by grain boundary reaction. Lartigue et al. [9] observed a certain activity of lattice dislocations only in the plateau regime, which these authors suggested were emitted from sliding grain boundaries for accommodation. The ability to emit lattice dislocations seems to be possessed only by the grain boundaries with yttrium just below the content of saturation. In free sintering, however, any lattice dislocation activity is not likely to contribute to densification, but the anomalous densification peak could correspond to an anomalous variation of the apparent diffusion coefficient.

\section{CONCLUDING REMARKS}

The alumina powder doped with $1500 \mathrm{ppm}$ yttria shows anomalous behavior at high temperature with grain size around $0.9 \mu \mathrm{m}$ : a second peak in densification rate during free sintering, and a stagnation followed by a steep increase in flow stress during sinter forging. These phenomena correspond to the creep plateau regime and to the saturation of grain boundary with yttrium. The grain boundary saturation occurs at a given grain size and it is inversely related to the doping level. This implies that finer grained alumina could be doped with higher yttria without grain boundary precipitation.

Yttrium segregation at grain boundary of alumina retards the densification in free sintering, and makes the flow stress higher in creep and sinter forging. It also lowers the grain size at which the transition in the rate controlling mechanism of deformation from grain boundary diffusion to interface reaction occurs.

\section{REFERENCES}

[1] COOK R. F., Acta Metall., 38 (1990) 1083.

[2] LI C. W. and KINGERY W. D., Adv. in Ceramics vol. 10, Ed. Kingery W. D., Am. Ceram. Soc. (1985) 368.

[3] HONDROS E. D. and SEAH M. P., Metall. Trans., 8A (1977) 1363.

[4] GRUFFEL P. and CARRY C., J. Europ. Ceram. Soc., 11 (1993) 189.

[5] GRUFFEL P. and CARRY C., Proc. 11th Riso Int. Symp. on Metallurgy and Materials Science, Eds. Bentzen J. J. et al., Riso Int. Lab. (1990) 305.

[6] AVERBACK R. S., HOFLER H. J., HAHN H. and LOGAS J. C., Nanostructured Materials, 1 (1992) 173.

[7] SATO E. and CARRY C., submitted to 3rd Europ. Ceram. Soc. Conf., Madrid, (1993).

[8] VENKATACHARI K. R. and RAJ R., J. Am. Ceram. Soc. 70 (1987) 514.

[9] LARTIGUE S., PRIESTER L., DUPAU F., and CARRY C., Mater. Sci. Eng., in press. 